\title{
Effect of capsaicin on electrical slow waves in the isolated cat colon ${ }^{1}$
}

\author{
S. ANURAS, J. CHRISTENSEN, ${ }^{2}$ AND D. TEMPLEMAN
}

From the Gastroenterology Research Laboratory, Department of Internal Medicine, University of Iowa, Iowa City, Iowa, USA

SUMMARY Because of the laxative effect of capsaicin, we examined the effect of that agent on the electromyogram of the isolated cat colon. At a concentration of $10^{-4} \mathrm{M}$, it caused a significant reduction in the frequency of the electrical slow waves in the proximal half of the colon. Frequency fell to its lowest value, $45 \%$ of control $(\mathbf{P}<0.001)$, in the most proximal $10 \%$ of the organ below the ileocecal junction, and the effect progressively diminished along the colon. In the distal half of the colon, the change in frequency was not significant. Sectioning of the colon into segments reduced the frequency of the slow waves in the proximal half of the colon, and capsaicin, in a concentration of $10^{-4} \mathrm{M}$, further reduced the frequency in the segments representing the proximal $30 \%$ of the colon. This effect of capsaicin is like that reported previously with other laxative agents.

The electromyogram of the circular muscle layer of the cat colon contains recurring signals called electrical slow waves. These are depolarisations and repolarisations of the muscle cell membranes recurring at reasonably regular intervals (Christensen et al., 1969). These signals occur throughout the colon. When records are made from multiple electrodes spaced at close intervals along the proximal half of the colon, the slow waves are seen to occur at the same frequency at all recording sites, locked in phase, with a phase lag which is cephalad-that is, they exhibit a pattern of spread such that they arise in the mid-colon and spread to the ileocecal junction. Thus, the midpoint of the colon serves as a pacemaker for slow waves for all of the colon proximal to that level, at least most of the time in vitro (Christensen et al., 1974).

As the slow waves of the colon seem to pace spike bursts and the contractions which accompany them, just as they do in the small intestine, it is proposed that the patterns of slow wave spread determine the patterns of contractions. It seems likely that patterns of contractions influence the flow of colonic contents. It has been proposed that some agents known

${ }^{1}$ This work was supported primarily by research funds from the Veterans Administration.

${ }^{2}$ Address for correspondence: Dr James Christensen, Gastroenterology Division, Department of Internal Medicine, University Hospitals, Iowa City, Iowa 52242, USA.

Received for publication 21 January 1977 to induce diarrhoea may affect the spread of slow waves in the colon, and this has been found to be true of ricinoleate (Christensen and Freeman, 1972), quinine, and quinidine (Barker and Christensen, 1973).

This project was undertaken to discover an effect upon the electrical slow waves of the colon of yet another agent that causes diarrhoea. The agent, capsaicin, is the pungent principle in the fruit of various species of Capsicum, the genus of hot peppers (Nelson, 1919). It is common experience that foods containing such peppers are laxative if taken in large quantity.

\section{Methods}

Cats weighing 1.5 to $4 \mathrm{~kg}$ were anaesthetised by intrapleural injection of sodium pentobarbital, 30 $\mathrm{mg}$ per $\mathrm{kg}$. The length of the colon was measured in situ, and whole colon was removed from the ileocecal junction to the anal verge. The stool was expressed manually and the colon was flushed with isotonic saline. The caecal tip was amputated, and the whole colon was everted over a hollow perforated Plexiglass mandrel. It was stretched to the length measured in situ, and pinned in place. The mandrel was immersed in a jacketed bath of Krebs' solution, maintained at 36.5 to $37.5^{\circ}$, and aerated with $95 \% \mathrm{O}_{2}-5 \% \mathrm{CO}_{2}$. A strip of mucosa was removed from the whole length of the colon to ex- 
pose a strip of the circular muscle layer about 0.5 $\mathrm{cm}$ wide along the mesenteric insertion. Sixteen silver-silver chloride glass pore electrodes were rigidly mounted in an electrode holder so that they were spaced along the colon at uniform intervals, usually about $2 \mathrm{~cm}$. Each electrode was lowered against the circular muscle layer until the electrical slow waves were recorded optimally. The electromyogram was recorded separately from all these electrodes against a common reference electrode, a coil of chlorided silver wire immersed in one corner of the bath, using a 16-channel polygraph. RC amplifiers were used with a time constant of one second and high frequency filters to reduce the amplitude of transients faster than about $30 \mathrm{~Hz}$.

In each experiment, a record was made for one to one and a half hours. Then capsaicin, dissolved in ethanol, was added to the 21 bath, the added volume never exceeding $2 \mathrm{ml}$. After an hour of recording, the capsaicin solution was removed and replaced with fresh Krebs' solution, and the recording was continued for a third hour. Three colons were studied using capsaicin at a bath concentration of $10^{-6} \mathrm{M}$ and three were studied at a concentration of $10^{-5} \mathrm{M}$. The effect of capsaicin at $10^{-4} \mathrm{M}$ was examined in eight preparations. The effect of ethanol in the volume indicated was examined in three colons. In five experiments, the cat colons were cut into $2 \mathrm{~cm}$ rings, and the experiments were carried out as above, using capsaicin $10^{-4} \mathrm{M}$.

Records were read visually by counting the number of slow waves occurring in each of the 16 tracings simultaneously for sequential 30-minute intervals throughout all three treatment periods. Fifteen to 30 minutes were allowed to elapse before the beginning of the first 30-minute period to stabilise the electromyogram. The frequencies were averaged and compared using the paired $t$ test.

\section{Results}

In the experiments carried out at the two lower concentrations, $10^{-6} \mathrm{M}$ and $10^{-5} \mathrm{M}$, no effect of capsaicin on slow wave frequency was seen, nor did ethanol alone influence the frequency.

At $10^{-4} \mathrm{M}$, capsaicin caused a significant reduction in the frequency of slow waves in the proximal half of the colon (Table 1). The frequency fell to its lowest value, $45 \%$ of control, in the most proximal $10 \%$ of the organ below the ileocecal junction, and the effect progressively diminished along the colon. In the distal half of the colon, the change in frequency was not significant. During the period of study after removal of the capsaicin, the frequency at all levels tended to return toward the pretreatment control period. A record of the electromyogram from one experiment is shown in the Figure.

Sectioning of the colon significantly reduced frequency of slow waves of the colon in the proximal half as previously described (Christensen et al., 1974). In colons that had been so sectioned, capsaicin, $10^{-4} \mathrm{M}$, significantly reduced the frequency of slow waves further in the proximal $30 \%$ of the colon, but it did not alter the slow wave frequency in the distal $70 \%$ (Table 2). The slow wave frequency tended to return toward normal after capsaicin was removed.

\section{Discussion}

Despite the very widespread consumption of capsaicin and the general recognition that hot peppers

Table 1 Mean frequency of slow waves of the cat colon in cycles/minute during control, treatment, and post-treatment periods

\begin{tabular}{|c|c|c|c|c|c|c|c|c|c|c|}
\hline & \multicolumn{10}{|c|}{ Distance along colon (\%) } \\
\hline & $0-10^{*}$ & $11-20$ & $21-30$ & $31-40$ & $41-50$ & $51-60$ & $61-70$ & $71-80$ & $81-90$ & $91-100$ \\
\hline \multirow{4}{*}{$\begin{array}{l}\text { Control period } \\
\text { Treatment period }\left(10^{-4} \mathrm{M}\right. \\
\text { capsaicin) } \\
\text { Percentage change } \\
\text { (treatment vs. control) } \\
\text { P value (treatment vs. } \\
\text { control) }\end{array}$} & $5.7 \pm 1.2$ & $5.6 \pm 0.6$ & $5.5 \pm 0.8$ & $5.7 \pm 0.6$ & $5.9 \pm 0.5$ & & $5.9 \pm 1.0$ & $6.0 \pm 0.6$ & $5.3 \pm 0.5$ & $5.0 \pm 0.4$ \\
\hline & $2 \cdot 6 \pm 1 \cdot 7$ & $3 \cdot 7 \pm 1 \cdot 6$ & $3.6 \pm 1.9$ & $3 \cdot 7 \pm 1 \cdot 8$ & $4 \cdot 3 \pm 1 \cdot 7$ & $4 \cdot 3 \pm 1 \cdot 7$ & $4 \cdot 6 \pm 1 \cdot 5$ & $5.3 \pm 0.6$ & $4 \cdot 1 \pm 0.5$ & $4 \cdot 6 \pm 0 \cdot 9$ \\
\hline & $45 \%$ & $67 \%$ & $66 \%$ & $65 \%$ & $73 \%$ & $70 \%$ & $78 \%$ & $87 \%$ & $77 \%$ & $92 \%$ \\
\hline & $<0.001$ & $<0.005$ & $<0.02$ & $<0.025$ & $<0.05$ & $<0.1$ & $<0 \cdot 1$ & $<0.02$ & $<0.01$ & $<0 \cdot 1$ \\
\hline \multirow{3}{*}{$\begin{array}{l}\text { Post-treatment period } \\
\text { Percentage change (post- } \\
\text { treatment vs. control) } \\
\text { P value (post-treatment } \\
\text { vs. control) }\end{array}$} & $4 \cdot 4 \pm 0.6$ & $4 \cdot 8 \pm 0 \cdot 4$ & $4.9 \pm 0.5$ & $4.9 \pm 0.4$ & $5 \cdot 0 \pm 0 \cdot 4$ & $5.4 \pm 0.8$ & $5 \cdot 1 \pm 0 \cdot 6$ & $4.9 \pm 0.6$ & $5 \cdot 1 \pm 0 \cdot 6$ & $5 \cdot 9 \pm 0 \cdot 1$ \\
\hline & $77 \%$ & $87 \%$ & $90 \%$ & $86 \%$ & $85 \%$ & $87 \%$ & $87 \%$ & $82 \%$ & $96 \%$ & $99 \%$ \\
\hline & $<0.001$ & $<0.2$ & $<0.2$ & $<0.2$ & $<0.1$ & $<0.1$ & $<0.2$ & $<0.2$ & $<0.4$ & $<0.4$ \\
\hline
\end{tabular}

*Each figure represents one-tenth of the length of the colon, beginning at the ileocolic junction. Thus, $0-10 \%$ means the most proximal one-tenth of the colon: excluding the caecum. 


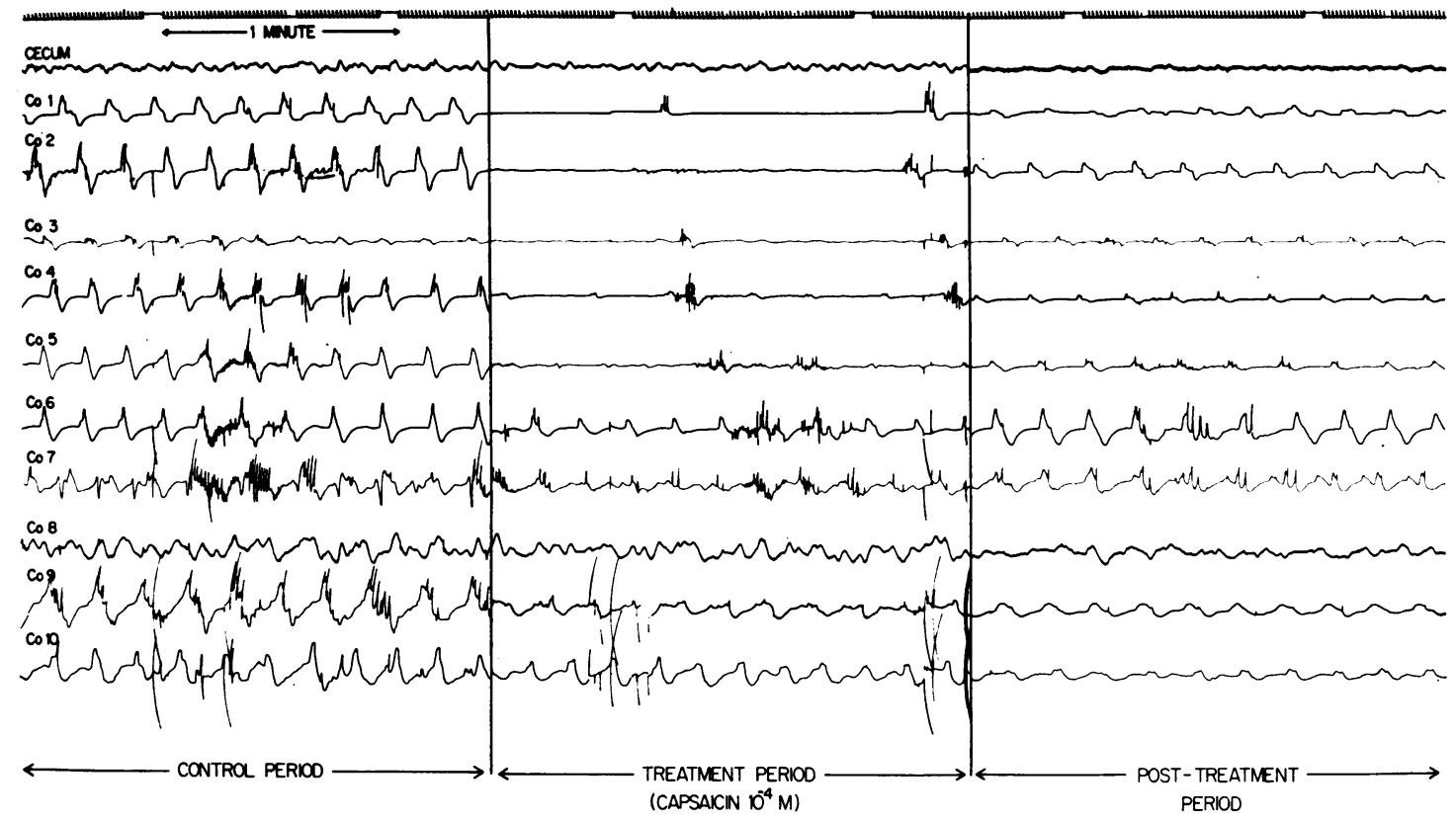

Figure A record of the electromyogram of the cat colon before, during, and after exposure to capsaicin. Time is marked at the top in seconds (ticks) and minutes (spaces). The three panels are not continuous, but were selected from one experiment at intervals of about 30 minutes. The symbols at the left indicate electrode positions, Co 1 being the first electrode distal to the ileocecal junction. In this experiment, the electrodes were about $2 \mathrm{~cm}$ apart.

Table 2 Mean frequency of slow waves of sectioning of cat colon in cycles/minute during control, treatment and post-treatment periods

\begin{tabular}{|c|c|c|c|c|c|c|c|c|c|c|}
\hline & \multicolumn{10}{|c|}{ Distance along colon (\%) } \\
\hline & $0-10$ & $11-20$ & $21-30$ & $31-40$ & $41-50$ & $51-60$ & $61-70$ & $71-80$ & $81-90$ & $91-100$ \\
\hline \multirow{6}{*}{$\begin{array}{l}\text { Control period } \\
\text { Treatment period }\left(10^{-4} \mathrm{M}\right. \\
\text { capsaicin) } \\
\text { Percentage change } \\
\text { (treatment vs. control) } \\
\text { P value (treatment vs. } \\
\text { control) } \\
\text { Post-treatment period } \\
\text { Percentage change (post- } \\
\text { treatment vs. control) } \\
\text { P value (post-treatment } \\
\text { vs. control) }\end{array}$} & $1.9 \pm 0.6$ & $2.5 \pm 0.8$ & $3 \cdot 1 \pm 0 \cdot 8$ & $4.5 \pm 0.5$ & $5 \cdot 0 \pm 0 \cdot 8$ & $5 \cdot 2 \pm 0 \cdot 9$ & $4 \cdot 7 \pm 0.7$ & $5 \cdot 0 \pm 0 \cdot 4$ & $5 \cdot 0 \pm 0 \cdot 6$ & - \\
\hline & $0.6 \pm 0.5$ & $1 \cdot 1 \pm 0.8$ & $1.9 \pm 0.9$ & $4 \cdot 2 \pm 1 \cdot 0$ & $5 \cdot 3 \pm 0.8$ & $5.5 \pm 0.8$ & $5 \cdot 2 \pm 1 \cdot 4$ & $5 \cdot 2 \pm 0 \cdot 8$ & $5 \cdot 1 \pm 1 \cdot 0$ & - \\
\hline & $33 \%$ & $45 \%$ & $62 \%$ & $93 \%$ & $106 \%$ & $105 \%$ & $110 \%$ & $104 \%$ & $102 \%$ & - \\
\hline & $\begin{array}{l}<0.02 \\
2.4 \pm 1.3\end{array}$ & $\begin{array}{l}<0.05 \\
2.7 \pm 0.6\end{array}$ & $\begin{array}{l}<0.05 \\
3.0 \pm 0.7\end{array}$ & $\begin{array}{l}<0.3 \\
4.2 \pm 1.0\end{array}$ & $\begin{array}{l}<0.2 \\
5.0 \pm 1.0\end{array}$ & $\begin{array}{l}<0.2 \\
5.0 \pm 0.8\end{array}$ & $\begin{array}{l}<0.7 \\
4.8 \pm 1.1\end{array}$ & $\begin{array}{l}<0.6 \\
5.3 \pm 0.4\end{array}$ & $\begin{array}{l}<0.7 \\
5.2 \pm 0.8\end{array}$ & - \\
\hline & $120 \%$ & $108 \%$ & $93 \%$ & $92 \%$ & $100 \%$ & $96 \%$ & $102 \%$ & $106 \%$ & $104 \%$ & - \\
\hline & $<0.5$ & $<0.95$ & $<0.20$ & $<0.60$ & $<0.50$ & $<0.80$ & $<0.80$ & $<0.20$ & $<0.20$ & - \\
\hline
\end{tabular}

affect the gut, there has been very little study of these effects. In the human stomach, observed gastroscopically, a $3 \%$ solution of capsaicin applied to the mucosa induces hyperaemia, oedema, and haemorrhage in $35 \%$ of cases (Viranuvatti et al., 1972). Capsaicin solutions introduced into the human stomach stimulate acid secretion in man (Ketusinh et al., 1966) but not in the cat (Toh et al., 1955).
Chronic ingestion of capsaicin by rats in a dose of $1 \mathrm{mg} / \mathrm{kg}$.day impairs intestinal absorption, reduces growth rate and causes ultrastructural alterations in intestinal mucosal cells (Nopanitaya, 1973, 1974).

Studies of the effects of capsaicin on smooth muscle are few indeed. Capsaicin induces contraction of the guinea-pig ileum preparation in vitro (Baraz et al., 1968). Injection of capsaicin into the 
superior mesenteric artery does not affect small intestinal motility (Toh et al., 1955).

Capsaicin is an extremely potent stimulant of neurosensory receptors. Thus, acute studies in animals of the effects of intravascular injection of the alkaloid usually end in the animal's death through excitation of receptors initiating cardiovascular reflexes (Toh et al., 1955; Baraz et al., 1968).

We found that the effect of capsaicin, a reduction of frequency of slow waves, could be explained in two ways. First, it could represent uncoupling of slow wave oscillators. This term is derived from the hypothesis that slow waves in the colon, like those of the small bowel, represent the output of a chain of relaxation oscillators coupled bidirectionally. In the colon, the evidence suggests that this chain is so oriented that the dominant oscillator (that with the highest intrinsic frequency) for the proximal colon is normally located at about the middle of the colon, so that the slow waves seem to arise at that point and to migrate cephalad. The evidence for that hypothesis came in part from experiments in which slow wave frequency was examined all along the colon in vitro before and after dividing it into serial segments (Christensen et al., 1974). In those studies, the frequencies of slow waves in all of the serial segments can be taken to represent the intrinsic frequency gradient along the proximal colon. When one compares that gradient with the one revealed in these experiments with capsaicin, a resemblance is apparent: in both cases, the experimental alteration depressed frequency in the first 10-percentile segment to about half, and the effect was progressively less in more distal segments along the colon. This suggests that the capsaicin effect is, indeed, an uncoupling of the slow wave oscillators. Second, capsaicin also further reduced the slow wave frequency in the proximal $30 \%$ of the colon after sectioning, indicating a direct depression of oscillator frequency.

Diarrhoea can be ascribed either to altered mucosal function or to abnormal motility in either the small intestine or the colon (Fordtran, 1967). We do not know if the effect of capsaicin on the electromyogram of the colon will explain the diarrhoea associated with its ingestion. In the human colon, mass movements increase in diarrhoeal states. There has been no study of mass movements in the cat colon. In the electromyogram of the isolated colon in cats with idiopathic diarrhoea, and in cats treated with castor oil to induce diarrhoea, there was uncoupling of the slow waves and reduction in the slow waves frequency in the proximal colon (Christensen et al., 1972). These changes were like the effects of capsaicin.

The average daily consumption of hot pepper in Thailand is $1 \mathrm{mg} / \mathrm{kg}$ of body weight, about $60-70 \mathrm{mg}$ of hot pepper per day (U.S. Interdepartmental Committee on Nutrition for National Defense, 1962). Capsaicin, $10^{-4} \mathrm{M}$, is equivalent to $30.5 \mathrm{mg} / \mathrm{l}$. The efficiency of the small bowel in absorbing capsaicin has not been studied. It is not possible, therefore, to estimate the proportion of ingested capsaicin that reaches the colonic mucosa.

\section{References}

Baraz, L. A., Khayutin, V. M., and Molnár, J. (1968). Analysis of the stimulatory action of capsaicin on receptors and sensory fibres of the small intestine in the cat. Further contribution to the problem of pain. Acta Physiologica Academiae Scientiarum Hungaricae, 33, 225-235.

Barker, J. D., and Christensen, J. (1973). Some effects of quinidine and quinine on the electromyogram of the colon. Gastroenterology, 65, 773-777.

Christensen, J., Anuras, S., and Hauser, R. L. (1974). Migrating spike bursts and electrical slow waves in the cat colon: effect of sectioning. Gastroenterology, 66, 240247.

Christensen, J., Caprilli, R., and Lund, G. F. (1969). Electric slow waves in circular muscle of cat colon. American Journal of Physiology, 217, 771-776.

Christensen, J., and Freeman, B. W. (1972). Circular muscle electromyogram in the cat colon: local effect of sodium ricinoleate. Gastroenterology, 63, 1011-1015.

Christensen, J., Weisbrodt, N. W., and Hauser, R. L. (1972). Electrical slow wave of the proximal colon of the cat in diarrhea. Gastroenterology, 62, 1167-1173.

Fordtran, J. S. (1967). Speculations on the pathogenesis of diarrhea. Federation Proceedings, 26, 1405-1414.

Ketusinh, O., Dhorranintra, B., and Juengjaroen, K. (1966). Influence of capsicum solution on gastric acidities. A preliminary report. American Journal of Proctology, 17, 511515.

Nelson, E. K. (1919). The constitution of capsaicin, the pungent principle of capsicum. Journal of the American Chemical Society, 41, 1115-1121.

Nopanitaya, W. (1973). Long term effects of capsaicin on fat absorption and the growth of the rat. Growth, 37, 269-279.

Nopanitaya, W. (1974). Effects of capsaicin in combination with diets of varying protein content on the duodenal absorptive cells of the rat. American Journal of Digestive Diseases, 19, 439-448.

Toh, C. C., Lee, T. S., and Kiang, A. K. (1955). The pharmacological actions of capsaicin and analogues. British Journal of Pharmacology, 10, 175-182.

U.S. Interdepartmental Committee on Nutrition for National Defense (1962). The Kingdom of Thailand: Nutrition Survey, pp. 57-59. Washington D.C.

Viranuvatti, V., Kalayasiri, C., Chearani, O., and Plengvanit, U. (1972). Effects of capsicum solution on human gastric mucosa as observed gastroscopically. American Journal of Gastroenterology, 58, 225-232. 